Ensaios Bibliográficos

\title{
A NOVA HISTÓRIA SOCIAL DO CRIME
}

THOMPSON, E.P. Senhores e Caçadores. Trad. Denise Bottmann. Rio de Janeiro, Paz e Terra, 1986.

José Jobson de Andrade Arruda ${ }^{1}$

Apraz-nos, sobremodo, a oportunidade de continuar este diálogo com a obra relevante deste acre historiador inglês que, a cada momento, nos surpreende com o estabelecimento de novos e insuspeitados paradigmas na urdidura de uma nova história social inglesa, ancorada na história da formação da classe operária, na sua vivência concreta e nas suas construções simbólicas mais amplas.

Senhores \& C'açadores, sexto volume da Coleção Oficinas da História, foi pensado inicialmente para compor uma das partes da coletânea Albion's Fatal Tree $^{2}$, publicado em 1975, mas cresceu em volume e importância a tal ponto que justificou-se uma publicação em separado, ocorrida no mesmo ano e reeditada em 1977. O livro representa, nos dizeres do próprio autor, uma série de experimentos, a começar pela redução, que segue a trilha do encaminhamento da pesquisa, reproduzindo em parte as vicissitudes e complexidades do pesquisador; negligencia as interpretações dos autores que analisaram o período imediatamente após os anos de 1723-1725, objeto do seu estudo, mergulhando em fontes manuscritas. À falta da documentação jurídica indispensável para seu estudo, à rarefação dos jornais, valeu-se das experiêcias dos moradores humildes e pobres das florestas, seguindo a trilha que os atava ao poder, encarando a sociedade de "baixo", como ela própria se via em 1723. Nestes termos, o episódico, o fragmento torna-se extremamente elucidativo e permite a

1 Depto. de História -FFLCH/USP.

2 Obra organizada por HAY, Douglas; LINEBAUGH, Peter e THOMPSON, E.P. publicada pela Allen Lane, em 1975. 
recuperação de eventos que se perderam para o conhecimento histórico e, até mesmo, para o conhecimento de seus coevos: "uma procisão com repolhos aqui, um repique de sinos ali, ...um panfleto na rua,...cartas anônimas, canções assobiadas, baladas cantadas nas tabernas".

Seu objetivo primacial era o estudo das origens da Lei Negra, decretada em maio de 1723 , e que de um só golpe criava 50 novos delitos capitais, delitos estes que analisados rigorosamente sob o império da lei, da formalização jurídica, do cutelo do poder, poderiam chegar a 200 ou 250 crimes passíveis de pena máxima. Enveredava Thompson pelas sendas tortuosas da história social do crime no século $\mathrm{XVIII}^{3}$, veredas estas que poderiam conduzi-lo ao próprio aparato do Estado britânico no século XVIII, Estado este que "existia para preservar a propriedade e, incidentalmente, as vidas e liberdades dos proprietários".

Seguindo a trajetória da pesquisa, o autor parte do delineamento do seu microcosmo social, a Floresta de Windsor. Para entender o mecanismo de poder ali instalado é levado à recomposição da administração da Floresta por volta de 1723, o poder burocrático florestal, pano de fundo indispensável à compreensão da Lei Negra, suas origens e desdobramentos sociais. Na Floresta não dominava a concórdia social. Pelo contrário, as tensões e conflitos pupulavam, "proprietários alodiais e arrendatários costumeiros estavam em conflito pelos direitos comunais, tanto com os funcionários da floresta, como com seus próprios senhores". Ainda mais, "como tais direitos eram amplos e válidos para todos os habitantes, é provável que os diaristas rurais tenham tomado o partido dos agricultores". Em meio ao conflitivo quadro social, ganha realce o papel dos Negros de Windsor, uma figura social compósita de bandidos sociais e rebeldes rurais, na concepção de Hobsbawm. "Florestanos armados", "gente do campo", que se habituara à resistencia armada aos parqueamentos privados, a usurpação das terras comuns, ao seu direito de cortar lenha, recolher turfa ou apresentar seus rebanhos, como define Thompson. Mas o universo dos "transgressores" é mais amplo e intrincado. Năo se reduz aos que pintavam seu rosto com fuligem, camuflando-se, os Negros, - estende-se por todos os escalões da estratificação

3 A história social do crime tem produzido revelações inusitadas Cf. LANE, Roger. Crime and the Industrial Revolution: British and American Views. Journal of Social History, v. 7, n. 3, p. 287-303, 1974. 
social, dos trabalhadores não-qualificados aos fidalgos, passando por artesãos, comerciantes e agricultores. Entre os primeiros, está o contingente mais numeroso; entre os fidalgos e baronetes o menos. Diaristas rurais, empregados fixos no campo e cavalariços de estalagens formam o estrato mais numeroso da "delinqüéncia" na Floresta de Windsor entre 1722-1724. O contingente de artesãos e agricultores vem logo a seguir.

Nas Florestas de Hampshire a ação de bandos de Negros incendiavam a imaginação popular, revivendo a lenda de Robin Hood, que se encarnou no "Rei John", um grupo de homens que se divertiam com exercícios viris e roubo de cervos, mais por galhofa do que por interesse material. Audazes, pareciam dotados de força mágica do ocultamento. Na verdade, moviam-se ocultos pela proteção popular, sob o manto de ressentimentos sedimentados por décadas. Audaciosos, anunciavam suas aparições, emergindo em meio a mais de $\mathbf{3 0 0}$ pessoas, contando não mais do que 15 membros, caras pintadas de preto, casacos e bonés de couro, liberados pelo "Rei John" que com seus "falsos pretos" apregoavam fidelidade ao Rei George, mas reservavam-se o direito de "fazer justiça e verificar que os ritos não insultassem nem oprimissem os pobres".

No lado oposto aos Negros, caçadores clandestinos, encontravam-se os senhores, os Whigs, que nos anos 20 formavam um conjunto heterogêneo de "especuladores políticos, traficantes de capitais, oficiais cevados nas guerras de Marlborough, dependentes oportunistas da justiça e da Igreja, e grandes magnatas fundiários". Não eram herdeiros da Revolução Puritana de 1640, mas sim da reação conservadora de 1688. "Vestiam desajeitadamente, como uma fantasia, a retórica libertária transmitida pelos seus ancestrais". A Lei Negra colocou um poder incomensurável em suas mãos para constrangimento daqueles aos quais consideravam um estorvo. Um instrumento legal que, "na melhor das hipóteses... tornou-se uma curiosa espécie de carta magna da morte para os legisladores do século 18". Por isto, Thompson considera que a vida política da Inglaterra nos anos 20 tinha algo de uma "república de bananas", na qual os "predadores lutam pelos espólios do poder e ainda não concordaram em se submeter a regras e formas racionais ou burocráticas".

$O$ duro embate entre os deserdados das Florestas e os guardas encarregados de submetê-los conseguiu apenas adiar a expropriação para o século XIX em alguns redutos, tais como a Floresta de Windsor, Nova Floresta de Dean. Os direitos de pastagem aí mantidos eram excepcionais, exatamente porque os conceitos de propriedade mantinham-se af "defasados em relação ao espírito da 
época". A transformação do conceito de propriedade no decurso da Revolução Inglesa do século XVII, na qual declina a noção de propriedade real em favor da propriedade iminente, relacionada ao possuidor, consolida-se no século XVIII, quando firma-se a jurisprudência em favor da propriedade absoluta dos bens, abolindo as formas arcaicas e pré-capitalistas de propriedades e direitos simultâneos. As reivindicações dos menos favorecidos, quando consideradas, eram estigmatizadas pelo espírito de caridade. As resistências, ao fechamento dos campos, por exemplo, identificada uma conjuração social, precipitavam a utilização da lei como peça estratégica no arsenal dos processos judiciais.

Exatamente neste ponto, quando ensaia reflexões sobre a natureza histórica da lei no século XVIII, Thompson torna-se um historiador instigante e criador. Investe contra o marxismo vulgar para o qual "o domínio da lei é apenas uma outra máscara do domínio de uma classe"; "fenômeno do poder e da hipocrisia da classe dominante". Nega o caráter de "já explicado"s da lei como elemento da superestrutura. Reconhece que a lei entendida como instituição ou pessoas pode ser" facilmente assimilada à lei da classe dominante". Mas, insiste que "a lei também pode ser vista como ideologia ou regras e sanções específicas, que mantêm uma relação ativa e definida com as normas sociais; e, por fim, pode ser vista simplesmente em termos de sua lógica, regras e procedimentos próprios isto é, simplesmente enquanto lei ${ }^{4}$. Neste contexto, a Lei Negra não expressa apenas a ascendência da oligarquia Whig e a busca de legitimação de sua propriedade. Reflete também outras formas de propriedade que estavam em jogo e que atingiam diretamente o interesse do proprietário rural, do trabalhador rural, dos funcionários das florestas, dos habitantes das florestas. A lei acabava por ser o fruto da prática efetiva nos campos e seguida desde tempos imemoriais. Por isso estava viceralmente "imbricada na própria base das relações de produção... endossada por normas tenazmente transmitidas pela comunidade", não podendo ser simplesmente descartada como ideologia.

Evidentemente, numa sociedade dominada pelo dissenso a lei era formulada e aplicada diretamente para impor o poder de classe e legitimá-lo. Sabidamente, a hegemonia da classe dominante inglesa do século XVIII

4 Neste mesmo sentido, ver MUNGER, Frank. Measuring Repression of Popular Protest by English Justices of the Peace in the Industrial Revolution. Historical Methods, v. 12, n. 2, p. 76-82, 1979. 
expressava-se, sobretudo, "pelos rituais de profunda meditação dos Juízes de Paz, pelas sessões trimestrais, pela pompa das sessóes judiciais e pelo teatro de Tyburn". Destarte, as relações de classe expressavam-se através das formas da $l e i$, que apresentam suas próprias características, história e lógica de desenvolvimento. Toda retórica do século XVIII inglês está saturada da noção de lei (grifo nosso), transformando seus emuladores em prisioneiros de sua própria retórica, retórica esta que permeava parte da multidão plebéia. A lei, por conter princípios de igualdade e universalidade, estendia-se, forçosamente à toda condição humana, transformando-se a necessidade em virtude.

De forma contundente, sarcasticamente, Thompson reverbera a história: "Se a lei é manifestamente parcial e injusta, não vai mascarar nada, legitimar nada, contribuir em nada para a hegemonia de classe alguma". Sua eficácia como intrumento de dominação é mostrar-se avessa às manipulações, parecer ser justa e sendo mesmo às vezes justa. Ideologia não é mera hiprocrisia. Mesmo os dominantes necessitam sentir-se legítimos no seu poder, moralizados em suas funções; sentiram-se úteis e justos. "A lei é, em sí mesma, um bem incondicional".

A obra jurídica do século XVI e XVII, respaldada pela ação dos revolucionários do século XVII, transmitiu-se como herança para o século XVIII, originando nas mentes de uns poucos homens a aspiração de ideais e valores jurídicos universais. "A retórica e as regras de uma sociedade são muito mais que meras imposturas", sentencia Thompson, "simultaneamente podem modificar em profundidade o comportamento dos poderosos e mistificar os destituídos do poder. Podem disfarçar as verdadeiras realidades do poder, mas ao mesmo tempo podem refrear esse poder e conter seus excessos".

O estudo de um objeto aparentemente limitado no tempo, no espaço e no tema, a Lei Negra, no ano de 1724 , em algumas florestas inglesas, mostrou-se proficuamente reveladora da natureza da sociedade e do poder na Inglaterra setecentista, sugerindo, aos historiadores, um campo ilimitado para suas pesquisas nos domínios da história social do crime. Michel Foucault já chamara atenção para os ritos da punição social, "a execução pública entendida, não somente como um ritual jurídico, mas também político. Ele pertence, mesmo em casos menores, à cerimônia pela qual o poder se manifesta" ${ }^{5}$. Neste sentido, as p. 47. 
execuções por crime de felonia, não podem ser descartadas como incompreensíveis e desimportantes. Têm a sua lógica no quadro da sociedade e săo fundamentais no sentido de revelar o processo de internalização da obediência ${ }^{6}$. A desobediência civil é aparentada da desobediência política. Por isso, mesmo que nâo se conseguisse provar nos tribunais que os Negros tivessem qualquer ligação com os radicais, jacobitas, o poder constituído esforçou-se por estabelecer estas conexões. Seria o potencial insurgente um dado imanente, parte de "uma cultura política compartilhada pelo povo em todas as áreas?"7

Senhores $e$ Caçadores constitui-se num livro fundamental à compreensäo, não apenas da sociedade inglesa setecentista, mas da formação da estrutura jurídica moderna na qual, diga-se de passagem, estão ausentes princípios democratizantes. Isto é, o corpo legal em construção reflete muito mais a reação conservadora, que se seguiu aos arroubos radicais urdidos no processo da Revolução Inglesa do século anterior. O conhecimento das leis em vigor, todavia, permite vislumbrar, de um lado, a permanéncia de um tipo de sociedade - a realeza e os senhores - e, de outro, a força incoercível das transformações atestadas na própria necessidade do poder em se expressar por via legal.Talvez por isso mesmo, o livro recupere a dupla dinâmica da estrutura judiciária inglesa: coibidora e inovadora.

Nesse passo, adquirem sentido as discussões que o autor mantem com o marxismo. A vertente marxista contra a qual invectiva, entretanto, reflete linhagens ancoradas em posturas oficiais, linhagens vulgares, que dão ao leitor em certas passagens a sensação de que o autor enfrenta moinhos de vento. Vale dizer, Senhores e Caçadores, responde às velhas lutas e oposiçōes travadas por um grupo de intelectuais ingleses no interior do Partido Comunista inglês, nos anos 50. Provavelmente seja por essa razão que o livro desconheça as contribuições marxistas e para-marxistas referentes aos problemas da ideologia e da cultura que, pelo menos desde os anos 30 e 40, já haviam sido feridos, sobretudo no segundo momento pela densa produção dos frankfurtianos.

Nesse fluxo de consideraçōes é possível extrair outros desdobramentos do livro de Thompson, que já se encontram presentes em suas publicações

6 Cf. J. A. SHAPE. Last dying speeches: religion, ideology and public execution in seventeentb-century England. Past \& Present, n. 107, p. 166-167.

7 UNDERDOWN, David. Rebel, Riot and Rebellion. Popular Politics and Culture in England, 1603-1660. Oxford, 1985, p. 121. 
anteriores, ou seja, o seu progressivo distanciamento do marxismo. Em Senhores $e$ Caçadores o autor deliberadamente não trabalha com categorias explicativas, como classe, por exemplo. Assim, ao recusá-las, a construção de sua obra passa a refletir esta postura, ou seja, o autor dá a seu livro o andamento da trajetória de sua pesquisa. $O$ conhecimento da História deixa de ser uma construção a partir da recuperação do processo de criação coletiva dos homens, para assemelhar-se ao processo de investigação do estudioso. Nesse passo, a ruptura de Thompson com o Partido Comunista inglês reverbera seu próprio distanciamento do marxismo, transformando o autor num tipo de pensador radical, assemelhado aos marginais que ele próprio buscou recuperar. Considerar tal dimensão da obra de Thompson, porém, recoloca um novo patamar de discussōes, patamar este que apenas enriquece o debate em torno do processo de conhecimento científico, mas que em nada diminui a densidade e a levesa de sua obra, após a qual, como disse Hobsbawm, "o século dezoito nunca mais será o mesmo". 